\title{
Within-person, between-person and seasonal variance in nutrient intakes among 4- to 8-year-old rural Zambian children
}

\author{
Bess L. Caswell ${ }^{1,2}$, Sameera A. Talegawkar ${ }^{3}$, Ward Siamusantu ${ }^{4}$, Keith P. West, $\mathrm{Jr}^{2}$ and Amanda C. Palmer ${ }^{2 *}$ \\ ${ }^{1}$ The Johns Hopkins Bloomberg School of Public Health, Center for Human Nutrition, Baltimore, MD 21205, USA \\ ${ }^{2}$ Institute for Global Nutrition, The University of California, Davis, Davis, CA 95616, USA \\ ${ }^{3}$ Department of Exercise and Nutrition Sciences, Milken Institute School of Public Health, The George Washington University, \\ Washington, DC 20005, USA \\ ${ }^{4}$ National Food and Nutrition Commission, Lusaka, Zambia \\ (Submitted 13 October 2019 - Final revision received 12 January 2020 - Accepted 11 February 2020 - First published online 26 February 2020)
}

\begin{abstract}
Estimates of the components of nutrient intake variation are needed for modelling distributions of usual intake or predicting the usual intake of individuals. Season is a potential source of variation in nutrient intakes in addition to within- and between-person variation, particularly in low- or middle-income countries. We aimed to describe seasonal variation in nutrient intakes and estimate within-person, between-person and other major components of intake variance among Zambian children. Children from rural villages and peri-urban towns in Mkushi District, Zambia aged 4-8 years were enrolled in the non-intervened arm of a randomised controlled trial of pro-vitamin A carotenoid biofortified maize ( $n$ 200). Up to seven 24-h dietary recalls per child were obtained at monthly intervals over a 6-month period covering the late post-harvest (August-October), early lean (November-January) and late lean (February-April) seasons (2012-2013). Nutrient intakes varied significantly by season. For energy and most nutrients, intakes were highest in the early lean season and lower in the late post-harvest and late lean seasons. Season and recall on a market day had the strongest effects on nutrient intakes among covariates examined. Unadjusted within- to betweenperson variance ratios ranged from 4.5 to 31.3. In components of variance models, season accounted for 3-20\% of nutrient intake variance. Particularly in rural settings in low- and middle-income countries, where availability of locally grown, nutrient-rich foods may vary seasonally, studies should include replicates across seasons to more precisely estimate long-term usual intakes.
\end{abstract}

Key words: Nutrient intake: Dietary assessment: Season: 24-h recall: Preschool-aged children: School-aged children: Sub-Saharan Africa

Estimates of dietary intakes are required to identify risks of inadequate nutrient intakes and to study associations between diet and health. Typically, the dietary exposure of interest in epidemiological studies is usual, or long-term average, intake of foods or nutrients ${ }^{(1)}$. However, because an individual's nutrient intakes vary from day to day, intake on a single day, as measured by 24-h dietary recall or food record, does not reflect usual intake ${ }^{(1-3)}$. In order to estimate usual intakes, observed nutrient intakes from a small number of dietary recalls should be adjusted to account for within-person, day-to-day variation. This can help to reduce bias in estimates of prevalence of inadequacy and measures of association with health outcomes and to increase power to detect differences in group mean intakes ${ }^{(1-4)}$. Estimates of within- and between-person variance derived from repeated observations can also be used to calculate the number of dietary observations needed to estimate usual nutrient intakes within a chosen range of precision or to conduct sensitivity analyses of prevalence estimates of inadequate intake or measures of association ${ }^{(2-8)}$. Studies without repeat observations may employ previously published values for within- and between-person variance to estimate usual intake distributions and prevalence of inadequacy ${ }^{(7,9)}$.

Estimates of components of nutrient intake variance are most useful when they represent the population under study. Estimates of within-person variability and the ratio of within- to between-person variance may differ by age, sex, body composition, country and season and change over time $\mathrm{e}^{(2,4,5,7,9-18)}$. Recent studies have documented within- and between-person nutrient intake variance among children and adolescents in high- and middle-income countries, and older studies from sub-Saharan Africa were conducted among pregnant women or among boys of primary school

* Corresponding author: Amanda C. Palmer, fax +1 410955 0196, email acpalmer@jhu.edu 
age $\mathrm{e}^{(5,10,11,14,16,17,19)}$. Few estimates are available for preschoolor primary school-aged children in sub-Saharan Africa. Further, evidence on the seasonal component of nutrient intake variance is needed to better describe usual nutrient intakes and plan future studies among children in sub-Saharan Africa. Seasonal variations in food consumption among children in Ghana, Malawi and Benin ${ }^{(20,21)}$, seasonal effects on nutrient intakes among pregnant Malawian women ${ }^{(17)}$ and evidence of seasonal variance from high-income countries ${ }^{(12,18)}$ demonstrate the need to estimate seasonal components of nutrient intake variance among children in rural settings of sub-Saharan Africa. In the present study, we quantify the sources of nutrient intake variance among 4- to 8-year-old children in rural Zambia, with particular focus on seasonality.

\section{Methods \\ Study context}

The data used in these analyses were collected as part of a feeding efficacy trial of pro-vitamin A biofortified maize. The trial was conducted in Mkushi District, Central Province, Zambia, in 2012-2013 ${ }^{(22)}$. The study area included towns and villages in this rural, agricultural district that were accessible by road year-round. We conducted a mapping and census of every household in the study area to identify those with an eligible child. Oral informed consent was obtained from respondents to the mapping and census. Children between 4 and 8 years old, not yet enrolled in school and living within about $500 \mathrm{~m}$ of a local site established by the study for meal provision, were eligible to participate in the study. All children meeting these eligibility criteria were eligible to enrol, including multiple children from the same household. The present study was conducted according to the guidelines laid down in the Declaration of Helsinki, and all procedures involving human subjects/ patients were approved by the Institutional Review Board of the Johns Hopkins Bloomberg School of Public Health (Baltimore, MD, USA) and the Ethics Review Committee of the Tropical Diseases Research Centre (Ndola, Zambia). Verbal informed consent was obtained from caregivers of all participant children. Verbal consent was witnessed and formally recorded.

The efficacy trial enrolled children from sixty-four geographic clusters, beginning in August 2012. Clusters were assigned by block randomisation to one of three groups: a treatment group receiving meals containing biofortified maize ( $n 543$ children in twenty-five clusters), a control group receiving meals containing traditional maize ( $n 481$ children in twenty-five clusters) and a non-intervened control group ( $n 202$ in fourteen clusters). Children in the treatment and control groups received breakfast and lunch $6 \mathrm{~d} /$ week for 6 months. Children in the nonintervened group participated in data collection activities over the same 6-month trial period; their households received a package of food at the conclusion of the trial that was comparable to amounts of food received by children randomised to receive regular meals. Intervention activities and data collection in all groups were completed in April 2013. The purpose of the non-intervened group was to provide comparison data on dietary intakes and food security in the study population, absent the effects of a feeding trial. Only data from the non-intervened group were used in this analysis.

\section{Data collection}

Data were collected through surveys at the efficacy trial baseline (August-September 2012), at five monthly monitoring visits over the course of the 6-month intervention and at follow-up (March-April 2013). Birthdates of participating children and household descriptors were collected at baseline. Twentyfour-hour dietary recalls were conducted in all survey rounds, for a total of up to seven recalls per child.

Dietary intake data were collected by intervieweradministered, tablet-based $24-\mathrm{h}$ recall. The recall was developed for use in the present study, as previously described by Caswell et al. ${ }^{(23)}$. The primary caregiver of each enrolled child was asked to describe all foods and beverages the child consumed between waking the previous morning and waking the morning of the interview. The respondent was asked to recall the type of food, the ingredients used in mixed dishes, the amount consumed and where the child obtained the food. The interviewer recorded food description data by selecting foods and ingredients from pre-set lists of local foods or by typing in a description of any item not in the pre-set lists. Photograph booklets showing ranges of portion sizes for each of thirteen commonly consumed foods were used for portion estimation of most foods. Portion sizes shown in the photograph booklets were based on focus groups of local mothers. For some foods, such as fruit or bread, the number of pieces consumed was recorded. After discussing the foods consumed throughout the day, the interviewer reviewed a picture chart with the respondent to identify any missed foods. Picture charts were provided to respondents $2 \mathrm{~d}$ before the recall interview, and respondents were asked to place tick marks by the foods the child consumed during the day before the interview. Finally, the interviewer did a final pass of probes, asking the mother to review the child's day one more time to recall whether there were any more foods that had been consumed.

Observed nutrient intakes were calculated from each 24-h recall by multiplying all ingredient or unmixed food weights by their nutrient contents and summing each nutrient over all foods consumed. Portion sizes of each food were converted to grams based on the gram weight of the portion shown in the selected photograph, with adjustment for relative density if the photographed food differed from the recalled food. Mixed foods were separated into ingredients and ingredient weights using a database of standard recipes (HarvestPlus, unpublished results) from a previous survey of dietary intakes among women and preschoolers in the same study area ${ }^{(24)}$. Nutrient contents of each food or ingredient were calculated using a local food composition table compiled primarily from two Zambian food composition tables, one by HarvestPlus (unpublished results) and one published by the National Food and Nutrition Commission of Zambia ${ }^{(25)}$. As needed, we also incorporated food composition data from the US Department of Agriculture's National Nutrient Database for Standard Reference, the Food and Agriculture Organization's International Network of Food Data Systems (INFOODS) Food Composition Tables for Biodiversity 2.0 and additional regional and global food composition tables ${ }^{(26-30)}$. 


\section{Data analysis}

All data calculation and analysis was conducted in SAS 9.4 (SAS Institute). Descriptive statistics were used to assess the distributions of household and child characteristics. Observed nutrient intakes were Box-Cox transformed prior to regression analyses to improve model fit and adherence to the assumption of a normal distribution of residuals. Individual recalls for which the child was reported ill were excluded from analyses. Results presented as means and confidence limits were backtransformed to the original scale of nutrient measurement.

We modelled nutrient intakes by season, dividing the study period into three seasons of approximately equal length and labelling them based on the agricultural calendar for a typical year in Zambia: late post-harvest season (August-October), early lean or planting season (November-January) and late lean season (February-April) ${ }^{(31)}$. Traditionally, post-harvest season is associated with adequate food stores from the prior harvest, while planting season is associated with risk of dwindling stores coupled with higher household energetic needs related to high farm labour demand, and late lean season is when risk of depleted household food stores is highest. To examine whether this agricultural pattern was associated with changing nutrient intakes, seasonal means were estimated and tested for significant differences using a longitudinal model with season as the fixed effect and an unstructured covariance model to control for correlation among repeat measures.

To estimate components of energy and nutrient intake variance, we fit a series of models of energy and nutrient intakes. We first fit unadjusted and adjusted models to estimate withinand between-person variance components overall and by age, sex and season subgroups. The unadjusted models included a child-level random intercept and no fixed effects and were fit using the full analytic sample and separately by age, sex and season subgroups. For the adjusted models, we added fixed effects to adjust for season, market day and interviewer, in addition to the child-level random intercept. This second set was fit among all participants and separately by age and by sex. When fitting this set of models by season, we retained the random intercept and fixed effects for market day and interviewer. Because multiple children were enrolled from some households and children were recruited from geographic clusters, we also tested models with household- and cluster-level random intercepts, in addition to the child-level intercept. These multi-level models either resulted in convergence errors or the cluster- and household-level random intercepts contributed very little to total variance (intraclass correlation coefficients $<0.05 \%$ ), so only the child-level random intercept was retained.

To estimate the contribution of season to total variance, we fit another series of unadjusted and adjusted models of energy and nutrient intakes. The unadjusted models to estimate seasonal variance included a child-level random intercept and random slope for season, with no fixed effects. For the adjusted models of seasonal variance, we added fixed effects for market day and interviewer to the random intercept and random slope for season.

Variables included in the adjusted models were chosen by developing a full model to identify recall- or child-level factors that were significantly related to observed nutrient intakes. Potential factors were identified from previous studies of nutrient intake variance ${ }^{(2,9-12,15,16,18,32)}$. We considered season, replicate number of each recall, day of the week, interviewer and whether the recall period fell on a market day as potential recall-level factors, and age and sex as potential child-level factors. We started with a null model including a child-level random intercept only, then added fixed effects one level at a time, starting with recall-level factors. At both levels, all potential covariates were tested and the covariates showing no or very few significant associations $(P<0.05)$ with intake over energy and all fourteen nutrients were dropped. When there was evidence of collinearity between two variables, as determined by correlation analysis and impact on regression coefficients, the variable with stronger associations among most nutrients was retained and the other variable dropped. Following previous authors, we controlled for interviewer in all analyses after determining that estimated energy intakes captured by three interviewers were lower on average than those from the other twelve interviewers $^{(2,12,15)}$. We also tested the full models of nutrient intakes excluding recalls collected by the three interviewers recording lower-than-average energy intakes. Because this did not substantially change results, we did not exclude their recalls from further analyses.

\section{Results}

We collected a total of 1279 unique 24-h dietary recalls from 202 children. After excluding recalls for which the child was reported ill ( $n 208$ observations), the final sample included 1071 observations among 200 children, with a mean of $5 \cdot 3$ (sD 1.2) observations per child. Therefore, results reflect nutrient intakes and nutrient intake variance among apparently healthy children, not yet enrolled in school and participating in a nonintervened, observational arm of a randomised, controlled feeding trial. Of the included recalls, 263 recalls among 187 children were collected during the post-harvest season (August-October), 506 recalls among 186 children were collected during the early lean season (November-January) and 302 recalls among 178 children were collected during the late lean season (February-April). The mean age was 5.5 (SD 1.2) years at baseline and $55 \%$ were male (Table 1). Heads

Table 1. Child and household characteristics of participants in the non-intervened arm of a biofortified maize efficacy trial in Mkushi, Zambia, 2012-2013

(Mean values and standard deviations; numbers and percentages)

\begin{tabular}{|c|c|c|c|c|}
\hline & Mean & SD & $n$ & $\%$ \\
\hline \multicolumn{5}{|l|}{ Child characteristics ( $n 200)$} \\
\hline Age (years) & 5.5 & $1 \cdot 2$ & & \\
\hline Under 5 years of age & & & 74 & 37 \\
\hline Male & & & 110 & 55 \\
\hline \multicolumn{5}{|l|}{ Household characteristics ( $n$ 157) } \\
\hline $\begin{array}{l}\text { Head of household can } \\
\text { read and write }\end{array}$ & & & 127 & 85 \\
\hline $\begin{array}{l}\text { Years of schooling completed by } \\
\text { head of household }\end{array}$ & $8 \cdot 1$ & $2 \cdot 7$ & & \\
\hline Rural residence & & & 79 & 50 \\
\hline
\end{tabular}


of household had completed $8 \cdot 1$ years of formal schooling, on average, and most could read and write. The mean asset score was 2.5 out of fifteen items included in the survey module on ownership of durable goods. The mean housing quality score, summing responses to questions on housing building materials, home size and sources of energy for light and cooking, was $22 \cdot 4$ out of an observed range of 14-40. Half of included households were located in regional towns and half were located in rural villages.

\section{Nutrient intakes by season}

Intakes of energy and all fourteen nutrients examined showed seasonal differences, though the magnitude of differences varied (Table 2). Mean energy intake was over $500 \mathrm{~kJ} / \mathrm{d}$ higher in the early lean season (November-January) than it was in the post-harvest (August-October) or late lean (February-April) seasons $(P<0 \cdot 05)$. This pattern was driven primarily by changes in carbohydrate intakes. Protein and fat intakes followed the same trend, but the magnitude of differences between seasons was small. A similar rise during the early lean season of intakes of B vitamins was observed. For three nutrients - Fe, $\mathrm{Zn}$ and vitamin $\mathrm{C}$ - intakes peaked in the early lean season and dropped to their lowest levels in the late lean season. Vitamin $\mathrm{B}_{12}$ and $\mathrm{Ca}$ intakes rose non-significantly between late post-harvest and early lean seasons and fell in late lean season. A notable exception to this general trend of rising in early lean season and falling in late lean season was intake of vitamin A, which decreased over the three seasons, though the difference in intakes in post-harvest and early lean seasons was marginally significant $(P=0.05)$. Though some seasonal differences in mean intake remained significant when adjusting for total energy intake, the trend weakened substantially for most nutrients (results not shown). In the energy-adjusted models, vitamin A intake retained a clear downward trend over the three seasons, and vitamin $\mathrm{C}$ intakes peaked in the early lean season.

\section{Components of variance in nutrient intakes}

Within- and between-person CV and the within- to betweenperson variance ratios based on unadjusted and adjusted models of nutrient intakes are presented in Table 3. Unadjusted variance ratios ranged from 4.5 for vitamin $B_{6}$ to 31.3 for vitamin $C$. Adjusting for season, interviewer and market day resulted in a slightly lower estimate of the variance ratio in most cases. For the majority of nutrients, the within-person CV was lower and the between-person CV was slightly higher when estimated by the adjusted model compared with the unadjusted model.

Though CV and variance ratios differed between children under 5 years old ( $n 405$ observations) and children aged 5 years and older ( $n 666$ observations), no strong trend for direction of difference was observed in either the unadjusted or adjusted models (online Supplementary Table S1). In both adjusted and unadjusted models, variance ratios were much higher among boys ( $n 593$ observations) than among girls ( $n 478$ observations), primarily related to higher betweenperson CV among girls (online Supplementary Table S2). Variance ratio, within-person $\mathrm{CV}$ and between-person $\mathrm{CV}$ varied by season (late post-harvest season: $n 263$ observations; early lean season: $n 506$ observations; late lean season: $n 302$ observations) but without clear trends in direction of difference (online Supplementary Table S3).

The contribution of a seasonal effect to total variance in energy and nutrient intakes is described in Table 4. In unadjusted models, the percentage of variance attributed to season ranged from $1.1 \%$ for vitamin A to $20.2 \%$ for riboflavin. In most cases, adjustment for interviewer and market day resulted in a slightly increased estimate of the percentage of variance attributable to

Table 2. Nutrient intakes by season among 4- to 8-year-old children ( $n 200)$ participating in the non-intervened arm of a biofortified maize efficacy trial, Mkushi, Zambia, 2012-2013

(Mean values and $95 \%$ confidence intervals)

\begin{tabular}{|c|c|c|c|c|c|c|}
\hline \multirow[b]{2}{*}{ Nutrient } & \multicolumn{2}{|c|}{$\begin{array}{l}\text { Late post-harvest season } \\
\text { (August-October) }\end{array}$} & \multicolumn{2}{|c|}{$\begin{array}{l}\text { Early lean season } \\
\text { (November-January) }\end{array}$} & \multicolumn{2}{|c|}{$\begin{array}{l}\text { Late lean season } \\
\text { (February-April) }\end{array}$} \\
\hline & Mean & $95 \% \mathrm{Cl}$ & Mean & $95 \% \mathrm{Cl}$ & Mean & $95 \% \mathrm{Cl}$ \\
\hline Energy $(\mathrm{kcal} / \mathrm{d})^{*}$ & $1441^{a}$ & 1373,1512 & $1578^{b}$ & 1528,1629 & $1457^{a}$ & 1406,1508 \\
\hline Protein $(\mathrm{g} / \mathrm{d})$ & $44^{\mathrm{b}}$ & 42,47 & $46^{b}$ & 44,48 & $43^{a}$ & 41,45 \\
\hline Fat $(g / d)$ & $42^{\mathrm{a}}$ & 39,45 & $45^{\mathrm{b}}$ & 43,48 & $44^{b}$ & 41,46 \\
\hline Carbohydrates (g/d) & $224^{\mathrm{a}}$ & 213,234 & $250^{\mathrm{b}}$ & 242,259 & $226^{a}$ & 218,233 \\
\hline $\mathrm{Ca}(\mathrm{mg} / \mathrm{d})$ & $241^{\mathrm{b}}$ & 222,260 & $249^{b}$ & 234,265 & $197^{\mathrm{a}}$ & 183,211 \\
\hline $\mathrm{Fe}(\mathrm{mg} / \mathrm{d})$ & $9 \cdot 2^{b}$ & $8 \cdot 7,9 \cdot 7$ & $9.9^{c}$ & $9 \cdot 5,10 \cdot 4$ & $8 \cdot 5^{a}$ & $8 \cdot 1,8.9$ \\
\hline $\mathrm{Zn}(\mathrm{mg} / \mathrm{d})$ & $5 \cdot 9^{b}$ & $5 \cdot 6,6 \cdot 2$ & $6 \cdot 3^{c}$ & $6 \cdot 0,6 \cdot 6$ & $5 \cdot 3^{a}$ & $5 \cdot 1,5 \cdot 6$ \\
\hline Vitamin A ( $\mu \mathrm{g}$ RAE/d) & $481^{b}$ & 437,528 & $430^{b}$ & 401,460 & $318^{\mathrm{a}}$ & 289,348 \\
\hline Thiamin (mg/d) & $0.74^{\mathrm{a}}$ & $0.69,0.78$ & $0.82^{b}$ & $0.78,0.87$ & $0.74^{\mathrm{a}}$ & $0.70,0.78$ \\
\hline Riboflavin (mg/d) & $0.61^{a}$ & $0.58,0.65$ & $0.71^{\mathrm{b}}$ & $0.68,0.74$ & $0.6^{\mathrm{a}}$ & $0.57,0.64$ \\
\hline Niacin $(\mathrm{mg} / \mathrm{d})$ & $10 \cdot 5^{\mathrm{a}}$ & $9 \cdot 7,11 \cdot 4$ & $11 \cdot 7^{b}$ & $11 \cdot 0,12 \cdot 4$ & $10 \cdot 4^{\mathrm{a}}$ & $9 \cdot 7,11 \cdot 1$ \\
\hline Vitamin $B_{6}(\mathrm{mg} / \mathrm{d})$ & $1 \cdot 2^{\mathrm{a}}$ & $1 \cdot 1,1 \cdot 3$ & $1 \cdot 3^{\mathrm{b}}$ & $1 \cdot 2,1.4$ & $1 \cdot 1^{\mathrm{a}}$ & $1 \cdot 1,1 \cdot 2$ \\
\hline Folate $(\mu \mathrm{g} / \mathrm{d})$ & $119^{a}$ & 110,129 & $142^{\mathrm{b}}$ & 135,150 & $128^{\mathrm{a}}$ & 120,136 \\
\hline Vitamin $B_{12}(\mu \mathrm{g} / \mathrm{d})$ & $0 \cdot 6^{b}$ & $0.53,0.67$ & $0.61^{\mathrm{b}}$ & $0.56,0.67$ & $0.47^{a}$ & $0.41,0.53$ \\
\hline Vitamin $C(\mathrm{mg} / \mathrm{d})$ & $33^{b}$ & 30,36 & $52^{c}$ & 46,58 & $27^{a}$ & 24,30 \\
\hline
\end{tabular}

RAE, retinol activity equivalents.

$\mathrm{a}, \mathrm{b}, \mathrm{c}$ Mean values within a row with unlike superscript letters were significantly different $(P<0.05, \mathrm{a}<\mathrm{b}<\mathrm{c})$.

* To convert kcal to $\mathrm{kJ}$, multiply by 4.184 . 
Table 3. Within- and between-person $\mathrm{CV}$ and within- to between-person variance ratios for energy and nutrient intakes, among 4- to 8-year-old participants in the non-intervened arm of a biofortified maize efficacy trial in Mkushi, Zambia, 2012-2013 (Coefficients of variation and variance ratios)

\begin{tabular}{|c|c|c|c|c|c|c|}
\hline \multirow[b]{2}{*}{ Nutrient } & \multicolumn{3}{|c|}{ Unadjusted models } & \multicolumn{3}{|c|}{ Adjusted models* } \\
\hline & $\mathrm{CV}_{w} \dagger$ & $\mathrm{CV}_{b} \ddagger$ & $\sigma_{w}^{2}: \sigma_{b}^{2}$ & $\mathrm{CV}_{w} \dagger$ & $\mathrm{CV}_{b} \ddagger$ & $\sigma_{w}^{2}: \sigma_{b}^{2}$ \\
\hline Energy $(\mathrm{kcal} / \mathrm{d}) \S$ & $19 \cdot 3$ & 7.5 & 6.6 & $18 \cdot 0$ & $7 \cdot 7$ & 5.4 \\
\hline Protein $(g / d)$ & 21.9 & $7 \cdot 2$ & $9 \cdot 3$ & $21 \cdot 3$ & $7 \cdot 4$ & $8 \cdot 3$ \\
\hline Fat $(g / d)$ & $20 \cdot 3$ & 8.8 & $5 \cdot 3$ & $19 \cdot 2$ & 8.8 & 4.7 \\
\hline Carbohydrates (g/d) & $20 \cdot 3$ & $6 \cdot 6$ & $9 \cdot 3$ & $19 \cdot 0$ & $7 \cdot 0$ & $7 \cdot 4$ \\
\hline $\mathrm{Ca}(\mathrm{mg} / \mathrm{d})$ & 28.4 & $7 \cdot 2$ & $15 \cdot 6$ & $30 \cdot 0$ & 8.3 & $13 \cdot 1$ \\
\hline $\mathrm{Fe}(\mathrm{mg} / \mathrm{d})$ & $19 \cdot 7$ & 5.0 & $15 \cdot 5$ & $19 \cdot 2$ & 5.0 & $14 \cdot 6$ \\
\hline $\mathrm{Zn}(\mathrm{mg} / \mathrm{d})$ & $21 \cdot 2$ & 7.9 & $7 \cdot 2$ & $20 \cdot 3$ & $8 \cdot 1$ & $6 \cdot 2$ \\
\hline Vitamin A ( $\mu \mathrm{g} R A E / d)$ & 34.8 & $9 \cdot 3$ & 14.0 & 37.4 & 9.7 & $15 \cdot 0$ \\
\hline Thiamin $(\mathrm{mg} / \mathrm{d})$ & $30 \cdot 7$ & $12 \cdot 6$ & 5.9 & $29 \cdot 0$ & $12 \cdot 3$ & $5 \cdot 6$ \\
\hline Riboflavin (mg/d) & $27 \cdot 3$ & $6 \cdot 9$ & $15 \cdot 5$ & $26 \cdot 4$ & 7.9 & $11 \cdot 2$ \\
\hline Niacin $(\mathrm{mg} / \mathrm{d})$ & $25 \cdot 2$ & $6 \cdot 6$ & 14.4 & 24.5 & 6.9 & 12.5 \\
\hline Vitamin $B_{6}(\mathrm{mg} / \mathrm{d})$ & $28 \cdot 2$ & $13 \cdot 2$ & 4.5 & $26 \cdot 9$ & 12.5 & 4.7 \\
\hline Folate $(\mu \mathrm{g} / \mathrm{d})$ & $18 \cdot 1$ & $5 \cdot 4$ & 11.4 & $17 \cdot 6$ & 5.5 & $10 \cdot 1$ \\
\hline Vitamin $B_{12}(\mu \mathrm{g} / \mathrm{d})$ & $63 \cdot 2$ & $19 \cdot 6$ & $10 \cdot 4$ & $66 \cdot 2$ & 21.5 & 9.4 \\
\hline Vitamin C $(\mathrm{mg} / \mathrm{d})$ & $30 \cdot 7$ & 5.5 & $31 \cdot 3$ & $31 \cdot 7$ & $6 \cdot 8$ & 21.9 \\
\hline
\end{tabular}

$\mathrm{CV}_{w}$, within-person $\mathrm{CV} ; \mathrm{CV}_{b}$, between-person $\mathrm{CV} ; \sigma_{w}^{2}: \sigma_{b}^{2}$, ratio of within-person variance:between-person variance; RAE, retinol activity equivalents.

${ }^{*}$ Model contains fixed effects for season, interviewer and market day.

$+\mathrm{CV}_{w}$, calculated as the square root of within-person variance divided by the mean.

$\ddagger \mathrm{CV}_{b}$, calculated as the square root of between-person variance divided by the mean.

$\S$ To convert kcal to kJ, multiply by $4 \cdot 184$.

Table 4. Within-person, between-person and seasonal components of variance as percentage of total variance and within- to between-person variance ratios for energy and nutrient intakes, among 4- to 8-year-old participants in the non-intervened arm of a biofortified maize efficacy trial in Mkushi, Zambia, 2012-2013

(Percentages)

\begin{tabular}{|c|c|c|c|c|c|c|c|c|}
\hline \multirow[b]{2}{*}{ Nutrient } & \multicolumn{4}{|c|}{ Unadjusted models } & \multicolumn{4}{|c|}{ Adjusted models* } \\
\hline & $\begin{array}{c}\text { Within-person } \\
(\%)\end{array}$ & $\begin{array}{c}\text { Between-person } \\
(\%)\end{array}$ & $\begin{array}{c}\text { Seasonal } \\
(\%)\end{array}$ & $\sigma_{w}^{2}: \sigma_{b}^{2}$ & $\begin{array}{c}\text { Within-person } \\
(\%)\end{array}$ & $\begin{array}{c}\text { Between-person } \\
(\%)\end{array}$ & $\begin{array}{c}\text { Seasonal } \\
(\%)\end{array}$ & $\sigma_{w}^{2}: \sigma_{b}^{2}$ \\
\hline Energy $(\mathrm{kcal} / \mathrm{d}) \dagger$ & $80 \cdot 7$ & $11 \cdot 0$ & $8 \cdot 3$ & $7 \cdot 3$ & 71.3 & $12 \cdot 1$ & $6 \cdot 2$ & 5.9 \\
\hline Protein $(\mathrm{g} / \mathrm{d})$ & $87 \cdot 2$ & 8.6 & 4.2 & $10 \cdot 1$ & 80.9 & 8.4 & 5.5 & $9 \cdot 7$ \\
\hline Fat $(g / d)$ & 81.9 & $15 \cdot 2$ & 2.9 & 5.4 & $76 \cdot 4$ & $16 \cdot 1$ & 2.9 & 4.8 \\
\hline Carbohydrates $(\mathrm{g} / \mathrm{d}$ ) & $81 \cdot 2$ & $6 \cdot 1$ & $12 \cdot 7$ & $13 \cdot 3$ & $70 \cdot 9$ & 7.5 & 8.0 & 9.4 \\
\hline $\mathrm{Ca}(\mathrm{mg} / \mathrm{d})$ & 87.6 & 3.4 & $9 \cdot 0$ & 25.5 & 83.2 & 3.0 & 11.6 & $27 \cdot 5$ \\
\hline $\mathrm{Fe}(\mathrm{mg} / \mathrm{d})$ & 91.1 & 4.5 & 4.3 & $20 \cdot 1$ & 85.0 & $4 \cdot 1$ & 4.6 & 20.8 \\
\hline $\mathrm{Zn}(\mathrm{mg} / \mathrm{d})$ & 84.3 & $10 \cdot 2$ & 5.5 & $8 \cdot 3$ & $77 \cdot 7$ & $10 \cdot 7$ & $3 \cdot 7$ & $7 \cdot 3$ \\
\hline Vitamin A ( $\mu \mathrm{g} R A E / d)$ & 92.5 & $6 \cdot 4$ & $1 \cdot 1$ & 14.4 & 88.5 & 4.9 & 3.5 & $17 \cdot 9$ \\
\hline Thiamin $(\mathrm{mg} / \mathrm{d})$ & $75 \cdot 0$ & 9.4 & $15 \cdot 6$ & 8.0 & $65 \cdot 1$ & 8.4 & 17.5 & $7 \cdot 7$ \\
\hline Riboflavin (mg/d) & 79.5 & 0.3 & $20 \cdot 2$ & $232 \cdot 8$ & 69.1 & $1 \cdot 1$ & 23.0 & 65.5 \\
\hline Niacin $(\mathrm{mg} / \mathrm{d})$ & $86 \cdot 7$ & $3 \cdot 3$ & $10 \cdot 0$ & $26 \cdot 3$ & 78.6 & 2.6 & $14 \cdot 3$ & $30 \cdot 7$ \\
\hline Vitamin $B_{6}(\mathrm{mg} / \mathrm{d})$ & $73 \cdot 3$ & $12 \cdot 7$ & 14.0 & $5 \cdot 8$ & $63 \cdot 3$ & $9 \cdot 0$ & $17 \cdot 3$ & $7 \cdot 0$ \\
\hline Folate $(\mu \mathrm{g} / \mathrm{d})$ & 84.6 & $5 \cdot 0$ & $10 \cdot 3$ & $16 \cdot 8$ & $80 \cdot 6$ & $6 \cdot 1$ & $9 \cdot 1$ & 13.2 \\
\hline Vitamin $\mathrm{B}_{12}(\mu \mathrm{g} / \mathrm{d})$ & 89.1 & 8.1 & 2.9 & 11.0 & 87.0 & 7.9 & $4 \cdot 1$ & 11.0 \\
\hline Vitamin C (mg/d) & 88.8 & 0.0 & $11 \cdot 2$ & - & 84.8 & 0.0 & $9 \cdot 4$ & - \\
\hline
\end{tabular}

$\sigma_{w}^{2}: \sigma_{b}^{2}$, ratio of within- to between-person variance; RAE, retinol activity equivalents. ${ }^{*}$ Model contains fixed effects for interviewer and market day.

† To convert kcal to kJ, multiply by $4 \cdot 184$.

season, so that variance attributed to season ranged from $2.9 \%$ for fat to $23.0 \%$ for riboflavin. With a random effect for season in the model, estimates of between-person variance as a percentage of total variance were low, ranging from 0 to $15.2 \%$. Further, the model including a seasonal random effect produced much higher estimates of the within- to between-person variance ratios than were seen in unadjusted models or models with season as a fixed effect.

\section{Discussion}

Data from seven repeat 24-h dietary recalls collected over 6 months revealed significant seasonal changes in intakes among Zambian children. Intakes of energy and most nutrients were highest between November and January, a period of time representing the planting and, traditionally, the early lean season. The relationship held for several nutrients when controlling for energy intake, indicating that the seasonal shift 
in intakes is not just in food quantity but also in nutrient density of the diet. Among children in this rural district of Zambia, the seasonal effect contributed to $2 \cdot 9-23 \%$ of total intake variances in adjusted models of variance components. In adjusted components of variance models, the within- to between-person variance ratios ranged from 4.7 for vitamin $B_{6}$ and fat to 21.9 for vitamin $\mathrm{C}$. The variance ratio for energy intake was $5 \cdot 4$.

Seasonal differences in food and nutrient intakes have been observed among children in other sub-Saharan African countries. Among 6- to 8-year-old children in rural Benin, food consumption patterns differed significantly between the postharvest and pre-harvest seasons, and intakes of vitamin $\mathrm{C}$ and fat were found to be higher in the post-harvest season ${ }^{(21)}$. Other nutrient intakes were not shown to differ significantly by season, though this may have been due to the study's small sample size and choice of micronutrients examined ${ }^{(21)}$. A study of 6- to 17-year-old Kenyan schoolchildren that examined nutrient intakes in the food shortage and harvest seasons found that intakes of energy, $\mathrm{Ca}$, vitamin $\mathrm{A}$, folate and vitamin $\mathrm{C}$ were significantly lower in the food shortage season ${ }^{(33)}$. Seasonal differences in foods consumed were also observed among 3- to 6-year-old children in rural Ghana and Malawi(20). Our results show that, despite likely changes in local and global food systems in the 10 or more years since these prior studies were published, agro-ecological season remains a factor to be controlled for in the design and analysis of dietary surveys.

Several factors, including agricultural work, holidays and local food availability, may contribute to the seasonal difference in energy and nutrient intakes among children in our study area. The early lean season, in which intakes of most nutrients were highest, corresponds to the maize planting season, when agricultural labour demands may cause changes to family activities and cooking patterns. Maize price stabilisation activities by the Food Reserve Agency of Zambia may mitigate household grain shortages that could occur during the planting season, enabling households to increase food intakes among all members ${ }^{(31,34)}$. An analysis of food security data collected concurrently with the diet data presented here found that food insecurity did not increase in what is traditionally regarded as the lean season ${ }^{(35)}$. The Christmas holiday also falls during this season. Though we did not find an effect of feast days on dietary intakes or a sharp increase in intakes in the days surrounding the holiday (data not shown), the holiday may provide an additional, partial explanation for the observed differences in dietary intake by season in this predominantly Christian population. Local food availability was considered one of the drivers of seasonal food consumption changes among Ghanaian and Malawian children ${ }^{(20)}$. In Zambia, the early lean season corresponds with mango season, and other seasonally available horticultural, wild or semi-cultivated crops may be contributing to nutrient intakes, as well. This hypothesis is supported by the substantial increase in vitamin $\mathrm{C}$ intakes in early lean season. Seasonal availability of local vegetable crops may also explain the decreasing trend in vitamin A intakes over the study period, particularly as a large proportion of vitamin A is obtained from plant sources in this population ${ }^{(36)}$.

The ranges of adjusted within- to between-person variance ratios that we report here (4.7-21.9) are higher than those reported in several previous papers on nutrient intake variance among children, though they were similar to those reported in two older studies conducted in the USA and the $\mathrm{UK}^{(4,9-11,17,32,37)}$. In contrast, Ollberding et al. ${ }^{(11)}$ found that the variance ratio ranged from 2.3 to 6.7 for boys and 2.6 to $4 \cdot 1$ for girls and was $2 \cdot 8$ for energy intake in both sexes among 6- to 11-year-old children in the USA. Among Belgian 4- to 6.5-year-olds, Huybrechts et al. ${ }^{(10)}$ reported variance ratios ranging from 1.0 to 2.9 . Earlier studies of nutrient intake variance among children have reported similarly low within- to between-person variance ratios ${ }^{(4,9,37)}$.

The high within- to between-person variance ratios we observed among 4- to 8-year-old Zambian children appear to be driven by low between-person variance rather than by high within-person variance. Compared with other studies conducted among children or in southern Africa that report values for within-person $\mathrm{CV}$, our results are similar ${ }^{(9,10,16,17)}$. We found within-person $\mathrm{CV}$ in adjusted models ranging from $17 \cdot 6$ to $37.4 \%$, excluding a high value of $66 \cdot 2 \%$ for vitamin $\mathrm{B}_{12}$. The range of within-person $\mathrm{CV}$ for 4 - to $6 \cdot 5$-year-old Belgian girls was $2 \cdot 6-36 \cdot 0 \%$ or, for boys, $18 \cdot 1-34 \%(10)$. Within-person $\mathrm{CV}$ in the present study are also similar in range to those reported for 8- to 9-year-old boys in Ghana, the Philippines, Finland, the Netherlands and Italy, and 9- to 17-year-olds in the USA and Russia ${ }^{(9,16)}$. In contrast, our values for between-person CV are generally lower than those reported for children in other regions or for Malawian women ${ }^{(9-11,17)}$. While the between-person $\mathrm{CV}$ estimated from our adjusted models of nutrient intakes range from 5.0 to $21.5 \%$, those reported for Belgian 4- to 6.5 year-olds range from 11.1 to $192.1 \%$ and those for US and Russian 9- to 17 -year-olds from $21 \cdot 5$ to $52 \cdot 0 \%^{(9,10)}$. Betweenperson $\mathrm{CV}$ among pregnant Malawian women ranged from 18 to $81 \%{ }^{(17)}$. One explanation for this result is that in this population drawn from a single, rural district, children have similar diets - regardless of socio-economic status or peri-urban residence - with meals typically consisting of stiff maize porridge accompanied by a small range of vegetable, fish or meat dishes. A second possible explanation for the low between-person variance is use of portion size photographs and standardised recipes in our tablet-based $24-\mathrm{h} \mathrm{recall} \mathrm{tool}^{(22,23)}$. Though portion size estimates were adjusted for food density, constraining participants to indicate one of five depicted portion sizes rather than indicating portion by food models may have contributed to the low between-person variance. Authors of two studies conducted in sub-Saharan Africa concluded that estimation of portion size using photographs performed acceptably for estimation of food intakes at the group level, but they did note that the method is subject to estimation error ${ }^{(38,39)}$. Among teenage Mozambiquan girls, Korkalo et al. ${ }^{(38)}$ found that portion sizes of foods similar to those consumed in Mkushi were, on average, underestimated by $5 \%$ when portion size photographs were used for estimating the amount of foods consumed in a prior meal. Huybregts et $a l{ }^{(39)}$ found that when women in rural Burkina Faso used photographs as a reference to estimate quantities of foods consumed the previous day, the average estimation error by type of food ranged from $-34 \mathrm{~g}$ for couscous to $12 \mathrm{~g}$ for liquid sauce. We used average recipes collected by a previous study conducted in the same district of Malawi, adjusted 
them to account for differences in reported ingredients and added recipes collected through focus group activities. Despite these efforts to match recipe calculations to the exact combination of ingredients reported by mothers in the 24-h recall, the use of standard recipes rather than household-specific recipes may have contributed to lower between-person variance.

Compared with other studies that have examined seasonal variance in nutrient intakes, we found a high percentage of total variance attributable to season. In contrast to the $2 \cdot 9-23 \%$ in this population, season contributed to less than $2 \%$ of total intake variances among US adults with overweight or obesity and less than $3 \%$ of total intake variances among Japanese women $^{(12,18)}$. Our estimates, however, cover 9 months of the year (August-April, corresponding to late post-harvest through late lean agricultural seasons), thus we cannot document whether further variation could be expected in the months not assessed in the present study (May-July, corresponding to the main harvest and post-harvest seasons) ${ }^{(31)}$. Our results showing that seasonal variance in nutrient intakes occurred even in the absence of increased food insecurity, along with prior studies showing that further changes may occur in harvest season $^{(17,20,33)}$, reinforce the importance of taking into account season in studies of nutrient intake, particularly among children living in rural, agricultural regions of low- and middle-income countries

With the advent of statistical methods and programmes for estimation of usual energy and nutrient intake distributions, such as those from the National Cancer Institute, Iowa State University or the European Food Consumption Validation Consortium, published estimates of within- and betweenperson components of nutrient intake variance take on purposes beyond calculating number of dietary replicates needed or adjusting measures of association as laid out in earlier studies ${ }^{(2,3,8,15,40,41)}$. As has been demonstrated by Jahns et $a{ }^{(7)}$ and Morimoto et al. ${ }^{(6)}$, external estimates of variance components may be used to adjust distributions of nutrient intakes in surveys with only one intake measure or to conduct sensitivity analyses on the effect of different variance component estimates on the usual nutrient intake distribution. However, without variance component estimates and study designs that account for a seasonal component of variance, these applications may introduce inaccuracy in the estimation of long-term usual nutrient intakes. In rural Zambia, mean energy and nutrient intakes varied systematically by season and the seasonal effect contributed as much as $23 \%$ of total intake variance. Even studies with long data collection periods that capture seasonal variation as part of within-person variance may miss a seasonal effect on mean intakes or misattribute seasonal variance to another component of variance if season is not considered in analyses. Ollberding et al. ${ }^{(11)}$ and Stote et al. ${ }^{(12)}$ provide examples of studies controlling for a potential seasonal effect on mean intakes.

\section{Conclusions}

Energy and nutrient intakes changed significantly by season among children in rural Zambia, and this seasonal effect contributed substantially to total nutrient intake variance. Between-person variance in nutrient intakes was low, giving rise to higher than expected within- to between-person variance ratios. Future studies should factor seasonality into both data collection and analysis to accurately estimate usual intakes, particularly in populations where diet is influenced by seasonal harvests of local horticultural and wild or semi-cultivated crops.

\section{Acknowledgements}

We wish to thank the children and families who participated in the biofortified maize trial. We acknowledge the support of Christopher Chibuye, Rose Mwana, Ngosa Molobeka and Edward Mupotola. We acknowledge Brian Dyer and Rolf Klemm at Johns Hopkins University for their contributions in developing the dietary recall method, and we thank Fabiana Moura, Mourad Moursi and Abdelrahman Lubowa at HarvestPlus for providing local food composition and standard recipe tables.

This work was funded by HarvestPlus Challenge grant no. 8251; the UK Department for International Development and the Sight and Life Global Nutrition Research Institute at Johns Hopkins University. The views expressed do not necessarily reflect those of HarvestPlus. The funders had no role in the design, analysis or writing of this article.

B. L. C. contributed to trial design and development of data collection tools, analysed dietary data, conducted statistical analyses and drafted the manuscript. S. A. T. supported analysis and interpretation, and edited and critically revised the manuscript. W. S. supervised field implementation and critically revised the manuscript. K. P. W. contributed to conception and design, provided guidance on analysis and critically revised the manuscript. A. C. P. designed the efficacy trial protocol, oversaw field work, contributed to analysis and interpretation, and edited and critically revised the manuscript.

The authors declare that there are no conflicts of interest.

\section{Supplementary material}

For supplementary material referred to in this article, please visit https://doi.org/10.1017/S0007114520000732

\section{References}

1. Willett W (2012) Nutritional Epidemiology, 3rd ed. New York: Oxford University Press.

2. Beaton GH, Milner J, Corey P, et al. (1979) Sources of variance in 24-hour dietary recall data: implications for nutrition study design and interpretation. Am J Clin Nutr 32, 2456-2559.

3. Liu K, Stamler J, Dyer A, et al. (1978) Statistical methods to assess and minimize the role of intra-individual variability in obscuring the relationship between dietary lipids and serum cholesterol. J Chronic Dis 31, 399-418.

4. Nelson M, Black AE, Morris JA, et al. (1989) Between- and within-subject variation in nutrient intake from infancy to old age: estimating the number of days required to rank dietary intakes with desired precision. Am J Clin Nutr 50, 155-167. 
5. Erkkola M, Kyttälä P, Takkinen H-M, et al. (2011) Nutrient intake variability and number of days needed to assess intake in preschool children. Br J Nutr 106, 130-140.

6. Morimoto JM, Marchioni DML, Cesar CLG, et al. (2012) Statistical innovations improve prevalence estimates of nutrient risk populations: applications in São Paulo, Brazil. J Acad Nutr Diet 112, 1614-1618.

7. Jahns L, Arab L, Carriquiry A, et al. (2005) The use of external within-person variance estimates to adjust nutrient intake distributions over time and across populations. Public Health Nutr 8, 69-76.

8. Iowa State University, Department of Statistics \& The Center for Agricultural and Rural Development (2003) PC-SIDE. Ames, IA: Iowa State University.

9. Jahns L, Carriquiry A, Arab L, et al. (2004) Within- and betweenperson variation in nutrient intakes of Russian and U.S. children differs by sex and age. J Nutr 134, 3114-3120.

10. Huybrechts I, De Bacquer D, Cox B, et al. (2008) Variation in energy and nutrient intakes among pre-school children: implications for study design. Eur J Public Health 18, 509-516.

11. Ollberding NJ, Couch SC, Woo JG, et al. (2014) Within- and between-individual variation in nutrient intake in children and adolescents. J Acad Nutr Diet 114, 1749-1758.

12. Stote KS, Radecki SV, Moshfegh AJ, et al. (2011) The number of $24 \mathrm{~h}$ dietary recalls using the US Department of Agriculture's automated multiple-pass method required to estimate nutrient intake in overweight and obese adults. Public Health Nutr 14, 1736-1742.

13. Morimoto JM, Marchioni DML, Cesar CLG, et al. (2011) Within-person variance for adjusting nutrient distribution in epidemiological studies. Rev Saude Publica 45, 621-625.

14. Pereira RA, Araujo MC, Lopes TDS, et al. (2010) Quantos recordatórios de 24-horas ou registros alimentares são necessários para estimar o consumo usual de energia e nutrientes? (How many 24-hour recalls or food records are required to estimate usual energy and nutrient intake?). Cad Saude Publica 26, 2101-2111.

15. Beaton GH, Milner J, McGuire V, et al. (1983) Source of variance in 24-hour dietary recall data: implications for nutrition study design and interpretation. Carbohydrate sources, vitamins, and minerals. Am J Clin Nutr 37, 986-995.

16. de Boer JO, Knuiman JT, West CE, et al. (1987) Within-person variation in daily dietary intake of boys from Finland, the Netherlands, Italy, the Philippines and Ghana. Hum Nutr Appl Nutr 41A, 225-232.

17. Nyambose J, Koski KG \& Tucker KL (2002) High intra/ interindividual variance ratios for energy and nutrient intakes of pregnant women in rural Malawi show that many days are required to estimate usual intake. J Nutr 132, 1313-1318.

18. Tokudome Y, Imaeda N, Nagaya T, et al. (2002) Daily, weekly, seasonal, within- and between-individual variation in nutrient intake according to four season consecutive 7 day weighed diet records in Japanese female dietitians. J Epidemiol 12, 85-92.

19. Verly E, Fisberg RM, Cesar CLGG, et al. (2010) Sources of variation of energy and nutrient intake among adolescents in São Paulo, Brazil. Cad Saúde Pública 26, 2129-2137.

20. Ferguson EL, Gibson RS, Opare-Obisaw C, et al. (1993) Seasonal food consumption patterns and dietary diversity of rural preschool Ghanaian and Malawian children. Ecol Food Nutr 29, 219-234.

21. Mitchikpe CES, Dossa RAM, Ategbo EA, et al. (2009) Seasonal variation in food pattern but not in energy and nutrient intakes of rural Beninese school-aged children. Public Health Nutr $\mathbf{1 2}$, 414-422.

22. Palmer AC, Siamusantu W, Chileshe J, et al. (2016) Provitamin A biofortified maize raises serum beta-carotene, but not retinol, in marginally nourished children: a cluster-randomized trial in rural Zambia. Am J Clin Nutr 104, 181-190.

23. Caswell BLBL, Talegawkar SASA, Dyer B, et al. (2015) Assessing child nutrient intakes using a tablet-based 24-hour recall tool in rural Zambia. Food Nutr Bull 36, 467-480.

24. Hotz C, Palaniappan U, Chileshe J, et al. (2011) Nutrition Survey in Central and Eastern Provinces, Zambia, 2009: Focus on Vitamin $A$ and Maize Intakes, and Vitamin $A$ Status among Women and Children. Washington, DC/ Lusaka, Zambia/Ndola, Zambia: HarvestPlus/National Food and Nutrition Commission of Zambia/Tropical Diseases Research Centre.

25. National Food and Nutrition Commission (2007) Food Composition Tables, 3rd ed. Lusaka, Zambia: National Food and Nutrition Commission.

26. Agricultural Research Service, United States Department of Agriculture (2013) USDA National Nutrient Database for Standard Reference, Release 26. Nutrient Data Laboratory Home Page. Beltsville, MD: Agricultural Research Service, United States Department of Agriculture

27. Agricultural Research Service, US Department of Agriculture (2014) USDA National Nutrient Database for Standard Reference, Release 27. Beltsville, MD: Agricultural Research Service, United States Department of Agriculture.

28. Charrondiere UR, Stadlmayr B, Rittenschober D, et al. (2012) Food Composition Database for Biodiversity Version 2.0 BioFoodComp2.O. Rome, Italy: FAO/INFOODS.

29. Korkalo L, Hauta-alus H \& Mutanen M (2011) Food Composition Tables for Mozambique. Helsinki, Finland: University of Helsinki.

30. Leung WW, Busson F \& Jardin C (1968) Food Composition Table For Use in Africa. Washington, DC/Rome: Food and Agriculture Organization/US Department of Health Education and Welfare.

31. FEWS Net (2013) Zambia Food Security Outlook: January to June 2013. Washington, DC: USAID

32. Miller JZ, Kimes T, Hui S, et al. (1991) Nutrient intake variability in a pediatric population: implications for study design. J Nutr 121, 265-274

33. Gewa CA, Murphy SP \& Neumann CG (2007) Out-ofhome food intake is often omitted from mothers' recalls of school children's intake in rural Kenya. J Nutr 137 , 2154-2159.

34. Food Reserve Agency. http://fra.org.zm/ (accessed June 2016).

35. Na M, Caswell BL, Talegawkar SA, et al. (2017) Monthly food insecurity assessment in rural Mkushi district, Zambia: a longitudinal analysis. BMC Public Health 17, 260.

36. Caswell BL, Talegawkar SA, Siamusantu W, et al. (2018) Usual nutrient intake adequacy among young, rural Zambian children. Br J Nutr 119, 57-65.

37. Lanigan JA, Wells JCK, Lawson MS, et al. (2004) Number of days needed to assess energy and nutrient intake in infants and young children between 6 months and 2 years of age. Eur J Clin Nutr 58, 745-750.

38. Korkalo L, Erkkola M, Fidalgo L, et al. (2013) Food photographs in portion size estimation among adolescent Mozambican girls. Public Health Nutr 16, 1-7.

39. Huybregts L, Roberfroid D, Lachat C, et al. (2008) Validity of photographs for food portion estimation in a rural West African setting. Public Health Nutr 11, 581-587.

40. National Cancer Institute (2012) SAS Macros for the NCI Method. Rockville, MD: National Cancer Institute.

41. Haubrock J, Nöthlings U, Volatier J-L, et al. (2011) Estimating usual food intake distributions by using the multiple source method in the EPIC-Potsdam Calibration Study. J Nutr 141, 914-920. 